\title{
Advances in $\mathrm{H}_{2}$ sensors for bioanalytical applications
}

\author{
Daoli Zhao, Tingting Wang and William R. Heineman* \\ Department of Chemistry, University of Cincinnati, Cincinnati, OH, 45221-0172, USA \\ Corresponding author: Tel.: +1-513-556-9210; fax: +1-513-556-9329 \\ E-mail address: William.Heineman@uc.edu \\ Tribute to Prof. Marco Mascini
}

\begin{abstract}
$\mathrm{H}_{2}$ sensors have been receiving more attention, especially with the development of $\mathrm{H}_{2}$ medicine and biodegradable alloys that produce $\mathrm{H}_{2}$. The $\mathrm{H}_{2}$ sensors discussed in this review are primarily the electrochemical, chemochromic metal oxides, and color indicator sensors. This review focuses on the bioanalytical application of these existing $\mathrm{H}_{2}$ sensors. The performance parameters of these sensors are reviewed to aid in identifying and selecting appropriate sensors for practical applications.

Key words: $\mathrm{H}_{2}$ sensors, $\mathrm{H}_{2}$ detection, biological applications, electrochemical sensors, metal oxides, color indicator

\section{Contents}

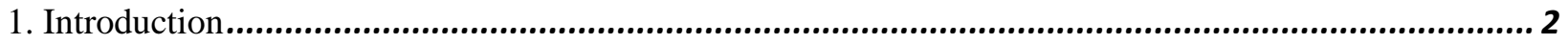

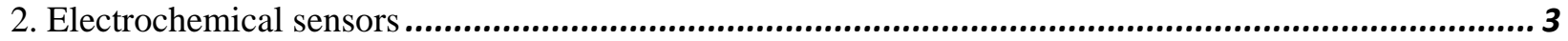

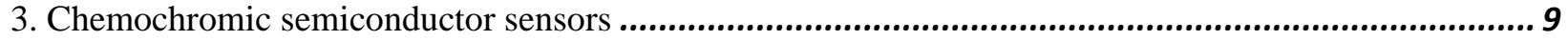

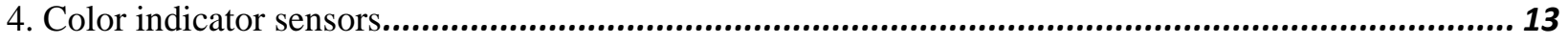

5. Comparison of electrochemical, chemochromic metal oxide and color indicator sensors.................... 16

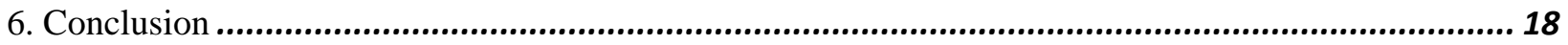

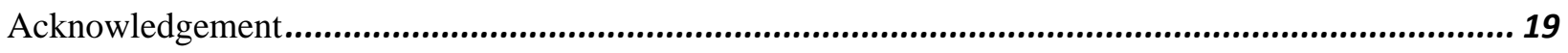

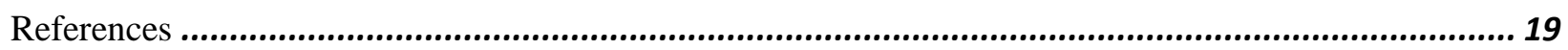




\section{Introduction}

Molecular hydrogen $\left(\mathrm{H}_{2}\right)$ has been receiving more and more attention due to its various novel medical and therapeutic applications with antioxidant and anti-inflammatory effects [1-5]. Inhaling $\mathrm{H}_{2}$ gas has been shown to be effective with rat models of acute inflammatory and oxidative diseases, including brain and myocardial infarction and post-cardiac arrest syndrome [5]. Moreover, inhalation of $\mathrm{H}_{2}$ gas strongly suppresses ischemic and reperfusion brain injury $[1,2]$. Additionally, consumption of water saturated with $\mathrm{H}_{2}\left(\mathrm{H}_{2}\right.$ water $)$ prevents stress-induced impairments in learning tasks during chronic physical restraint [3] by buffering the effects of oxidative stress or superoxide formation [6]. $\mathrm{H}_{2}$ has advantages as a potential antioxidant without adverse effects: it is mild enough to neither disturb metabolic redox reactions nor to affect reactive oxygen species (ROS), which function in cell signaling [7-10]. It has low affinity for physical ROS, and directly eliminates hydroxyl radical. In addition, it has favorable distribution characteristics because of its physical ability to penetrate biomembranes and diffuse through barriers into cellular components. Due to these important advantages, $\mathrm{H}_{2}$ has been used for oxidative stress-mediated disease, such as brain stem infraction, diabetes mellitus, neurodegenerative diseases or rheumatoid arthritis. One of the vital parameter for molecular $\mathrm{H}_{2}$ application is its concentration, making the detection of $\mathrm{H}_{2}$ concentration in vivo and in vitro desirable. So far, the measurement of $\mathrm{H}_{2}$ concentration in the blood for animals is mostly done by gas chromatography. The instruments are large, expensive and require trained personnel. Therefore, portable and less expensive detection methods are needed for in vivo and in vitro studies.

Biodegradable metals such as $\mathrm{Mg}$ and its alloys provide many advantages over the stainless steel and titanium permanent implants used today such as for bone repair [11]. Magnesium 
biodegradation rate is one of the crucial parameters to evaluate for their biomedical applications. Magnesium and its alloys degrade in aqueous environments, generating magnesium $\left(\mathrm{Mg}^{2+}\right)$ and hydroxyl $\left(\mathrm{OH}^{-}\right)$ions, as well as $\mathrm{H}_{2}$ gas. Therefore, measuring $\mathrm{H}_{2}$ evolution rate is equivalent to measuring the biodegradation or corrosion rate of a magnesium alloy. So far, the measurement of $\mathrm{H}_{2}$ evolution is mostly performed in vitro by measuring the generated $\mathrm{H}_{2}$ volume. However, this measurement is cumbersome, and suffers from $\mathrm{H}_{2}$ gas leaking. Therefore, a simple and effective $\mathrm{H}_{2}$ sensing method in vivo is desirable.

So far, the research and review articles on $\mathrm{H}_{2}$ sensors have focused on detecting $\mathrm{H}_{2}$ leaks associated with transportation pipes and fuel cells. Although the application of $\mathrm{H}_{2}$ sensors in bioanalysis is increasing, this growing area has yet to be reviewed. This review focuses on $\mathrm{H}_{2}$ sensors as related to bioanalytical applications.

\section{Electrochemical sensors}

Electrochemical $\mathrm{H}_{2}$ sensors are devices for detecting $\mathrm{H}_{2}$ concentration that are dependent on electrochemical reactions at the sensing electrode. The signal from an electrochemical cell changes in proportion to the $\mathrm{H}_{2}$ concentration at the electrode surface [12]. Electrochemical $\mathrm{H}_{2}$ sensors offer the advantages of room temperature operation and low power consumption. A market survey found that electrochemical $\mathrm{H}_{2}$ sensors are commercially more available than any other types [13]. The fundamentals of the major categories of electrochemical sensors (amperometric, potentiometric, and conductometric) have been reviewed in detail by Korotcenkov et al. [14]. Briefly, in the most commonly adopted two-electrode amperometric $\mathrm{H}_{2}$ sensor system, $\mathrm{H}_{2}$ diffuses through a gas permeable layer to the sensing electrode ( $\mathrm{Pt}$ and $\mathrm{Pd}$ ) at which the oxidation of $\mathrm{H}_{2}$ takes place. The potential between the working and reference electrodes is maintained constant. The electric current generated through electron transfer with 
$\mathrm{H}_{2}$ is proportional to the concentration of $\mathrm{H}_{2}$ according to Faraday's law [14]. Different from the amperometric sensors, $\mathrm{H}_{2}$ determination with a potentiometric sensor measures the potential difference between the sensing and reference electrodes at zero current where the redox reaction is at equilibrium. The $\mathrm{H}_{2}$ concentration is obtained based on the Nernst equation [13-14]. Unlike the amperometric and potentiometric $\mathrm{H}_{2}$ sensors, the conductometric $\mathrm{H}_{2}$ sensor detects solution resistance, therefore, it is not $\mathrm{H}_{2}$ selective. However, the much higher conductivity of proton compared with ions generated from other gases enables it to achieve similar selectivity to $\mathrm{H}_{2}$ as the other two electrochemical sensors [14].

A Clark-type $\mathrm{H}_{2}$ microsensor was first described in 1991 [15]. It operated with a Pt anode in acidic electrolyte environment and responded to $\mathrm{H}_{2}$ concentration. However, it was extremely unstable and could lose sensitivity to $\mathrm{H}_{2}$ within hours. Later on, newer versions of the Clark-type $\mathrm{H}_{2}$ sensor with higher stability were commercialized [16].

In vivo $\mathrm{H}_{2}$ sensing was first applied to a study of correlating $\mathrm{H}_{2}$ level with colonization of $H$. pylori in the stomach [17]. During the procedure, mice were kept fully anesthetized and the tissue was surgically exposed. $\mathrm{H}_{2}$ concentration was determined by inserting the electrochemical $\mathrm{H}_{2}$ microsensor ( $\mathrm{H}_{2}-50$, Unisense) into the mucus lining area of the mouse stomach through an incision. The amperometric $\mathrm{H}_{2}$ microsensors had high sensitivity towards $\mathrm{H}_{2}$ with a detection limit of $0.1 \mu \mathrm{M}$ according to the manufacturer. The procedure was repeated for up to eight sites per mouse stomach. The $\mathrm{H}_{2}$ level was calibrated by standard curves using a calibration chamber as described by the manufacturer [17]. This $\mathrm{H}_{2}$ measurement strategy was adapted in a study subsequent to that, where the same type of $\mathrm{H}_{2}$ microsensor was used for detecting $\mathrm{H}_{2}$ in mouse liver [18]. This sensor was also used to determine bone blood flow by monitoring an $\mathrm{H}_{2} / \mathrm{O}_{2}$ mixture during its washout in the blood flow. It requires breathing an $\mathrm{H}_{2} / \mathrm{O}_{2}$ mixture until the $\mathrm{H}_{2}$ 
levels of the gas equilibrate in the tissue. The gas mixture flow is then stopped, resulting in a washout rate of tissue $\mathrm{H}_{2}$ that is proportional to the blood flow according to equation [19]:

$$
C=C_{0} e^{-K t}
$$

Where $C$ is the $\mathrm{H}_{2}$ concentration at time $t, C_{0}$ is the original $\mathrm{H}_{2}$ concentration, $K=F / \lambda, F$ is the flow rate ( $\mathrm{mL} / \mathrm{min}), \lambda$ is the partition coefficient of $\mathrm{H}_{2}$ in tissue, and $t$ is the time.

In the promising field of developing biodegradable metals for medical applications, $\mathrm{H}_{2}$ sensing has become a unique application for evaluating biomedical materials because $\mathrm{H}_{2}$ is a product of metal biodegradation. We and others are developing nontoxic, light weight, rapidly biodegradable metallic biomaterials to replace permanently implanted metals as internal fixtures to aid the healing of fractured bones and tissue [20]. $\mathrm{Mg}$ and its various alloys are the major materials of interest in this research, which have been fabricated and tested in vitro and in vivo.

The first application of $\mathrm{H}_{2}$ measurement with the $\mathrm{H}_{2}-50$ electrochemical sensor was to investigate the formation of gas cavities caused by Mg alloy (Mg-4 wt.\% Y-0.5 wt.\% Gd-2 wt.\% Nd-0.5 wt.\% Dy) implanted subcutaneously in mice for in vivo testing [21]. The formation of these cavities was widely reported and the composition and concentration of each component of the gas was the subject of much debate in the field [22]. It was often assumed that gas cavities that formed during $\mathrm{Mg}$ material corrosion in vivo contained primarily $\mathrm{H}_{2}$ until a recent study carried out by our group, using the $\mathrm{H}_{2}-50$ microsensor proved that $\mathrm{H}_{2}$ exchanges rapidly with the surrounding tissue in mice [21]. A $1 \mathrm{~cm}$ long incision in the mouse skin was made to give access to the gas cavity adjacent to an implanted $\mathrm{Mg}$ sample. Measurements of $\mathrm{H}_{2}$ showed that the levels were actually very low, less than $1.2 \% \mathrm{v} / \mathrm{v}$ in either 2 -day or 10 -day monitoring. The high sensitivity and fast response enabled measurements both in the cavities and on the surface of the gas cavities using a micropositioner to hold the sensor (Fig. 1a). The results were confirmed by 
collecting gas in the cavity for analysis by mass spectrometry [21]. In a subsequent study, $\mathrm{Mg}$ materials were subcutaneously implanted in mice and instead of making an incision for the $\mathrm{H}_{2}$ measurement, detection was made non-invasively by pressing the sensor tip on the surface of the mouse skin. Because of the rapid exchange of $\mathrm{H}_{2}$ through the skin, the $\mathrm{H}_{2}$ concentration can indicate the rate of corrosion of an implanted $\mathrm{Mg}$ sample. Typical measurements made on the skin on top of the gas cavity and far away from the gas cavity are shown in Fig. 1b. As seen, the $\mathrm{H}_{2}$ microsensor response is very fast - less than $1 \mathrm{~min}$. Some variability in $\mathrm{H}_{2}$ was found depending on exactly where the tip was placed on the cavity. When the sensor tip was moved off of the cavity, $\mathrm{H}_{2}$ was still detected from the skin immediately adjacent to the cavity, but at considerably lower concentrations. The $\mathrm{H}_{2}$ microsensor was used to map out the $\mathrm{H}_{2}$ permeating through the skin. A good correlation between the $\mathrm{H}_{2}$ levels with the corrosion rate was established based on this study [23-27].
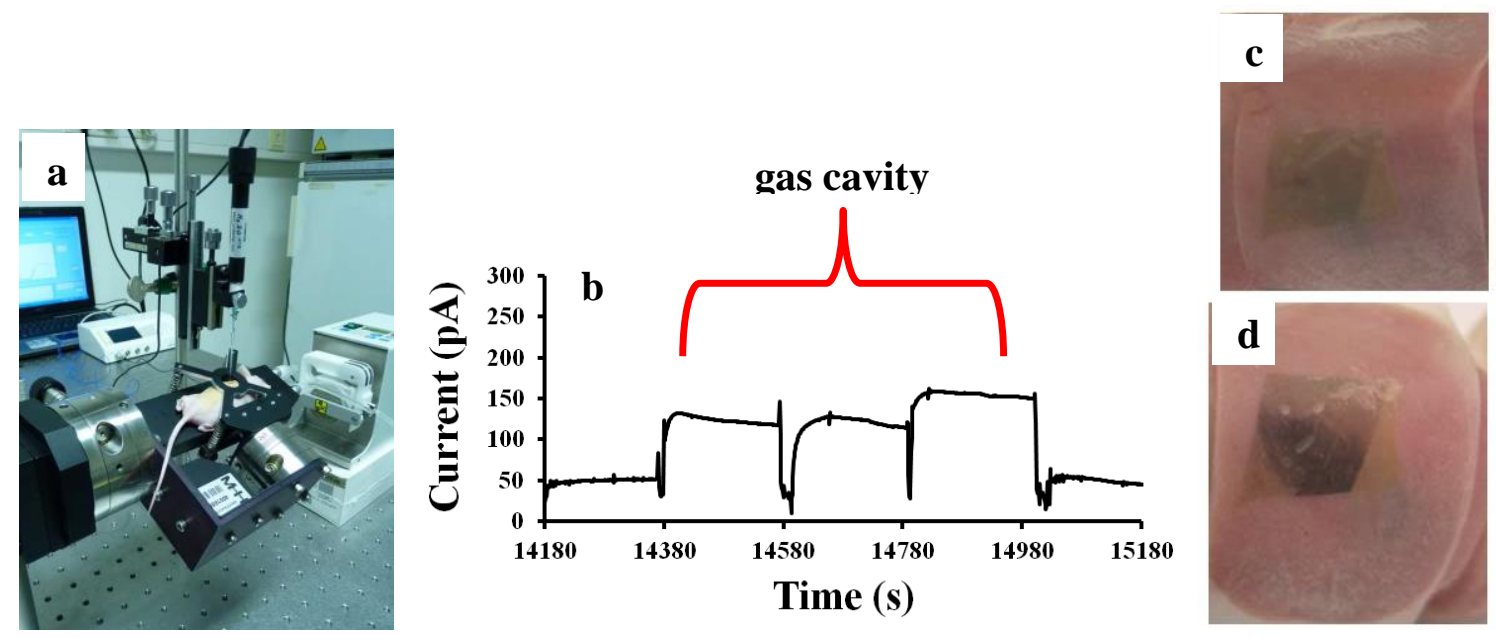

Fig. 1. $\mathrm{H}_{2}$ concentration measurements in vivo. (a) Experimental apparatus with an anesthetized mouse positioned on a swiveling table. $\mathrm{A}_{2}$ microsensor is mounted in a micromanipulator and positioned in an incision in the skin of the hairless mouse. (Reprinted from Acta Biomater., Vol 9, J. Kuhlmann, I. Bartsch, E. Willbold, S. Schuchardt, O. Holz, N. Hort, D. Hoche, W.R. 
Heineman and F. Witte, Fast escape of hydrogen from gas cavities around corroding magnesium implants, p. 8714-8721 (ref 21). Copyright (2013), with permission from Elsevier.). (b) Noninvasive $\mathrm{H}_{2}$ measurement through the skin above a gas cavity and far from the cavity on a mouse with a sample of Mg single crystal implanted subcutaneously on its back. (c) Response of the thin film visual $\mathrm{H}_{2}$ sensor from Element One before and (d) after 60 min exposure to $\mathrm{H}_{2}$ permeating through the mouse skin from implanted biodegrading Mg.

Although the $\mathrm{H}_{2}-50$ microsensor is a very sensitive and relatively stable $\mathrm{H}_{2}$ sensor, its fragility is a concern, especially when inserting into tissue is required for in vivo experiments. Even when non-invasive experiments are done, such as the measurement of $\mathrm{H}_{2}$ escaping from mouse skin above a Mg implant, gentle movement of the mouse can damage the sensor tip. Recently a more robust needle type amperometric $\mathrm{H}_{2}$ sensor $\left(\mathrm{H}_{2}-\mathrm{N}\right.$ needle sensor and $\mathrm{H}_{2}-\mathrm{NP}$ needle sensor for piercing, Unisense) was introduced for biomedical applications. In the $\mathrm{H}_{2}-\mathrm{N}$ sensor, instead of having a glass tip, a steel needle is mounted on the sensor for protection purposes. The first study using the $\mathrm{H}_{2}-\mathrm{N}$ sensor was carried out by Hayashida et al. by directly placing the sensor into tissues to investigate $\mathrm{H}_{2}$-dependent cardioprotection against ischemia-reperfusion injuries in rats in 2008 [28]. In a study conducted by Kajiya et al., intestinally produced $\mathrm{H}_{2}$ was determined to suppress inflammation in the liver and prevent the development of dextran sodium sulfateinduced colitis [29-30]. The $\mathrm{H}_{2}-\mathrm{N}$ sensor was placed into organs - small intestine, larger intestine, caecum, liver, spleen and brain - after sacrifice and blood $\mathrm{H}_{2}$ levels were monitored by cardiac puncture using the $\mathrm{H}_{2}-\mathrm{N}$ sensor [29]. Kamimura et al. used the $\mathrm{H}_{2}-\mathrm{N}$ sensor to monitor the dynamic movement of $\mathrm{H}_{2}$ in the liver after oral administration of $\mathrm{H}_{2}$-water to assess the biomedical treatment for obesity, and levels of $\mathrm{H}_{2}$ in the liver were monitored by directly 
inserting a needle-type $\mathrm{H}_{2}$ sensor into the liver for an hour [31]. The $\mathrm{H}_{2}$ concentration profile gave a peak 5 min after administration of $\mathrm{H}_{2}$-water in both fed and fasted livers (Fig. 2). A significant difference was found between the fed and fasted livers; the maximum $\mathrm{H}_{2}$ level in the fed liver was two-fold that of the fasted liver. Moreover, the fed liver maintained a considerable $\mathrm{H}_{2}$ level for an hour, while that in the fasted liver returned to the basal level after $25 \mathrm{~min}$. A correlation between glycogen concentration and accumulated $\mathrm{H}_{2}$ was found using a $\mathrm{H}_{2}-\mathrm{N}$ microsensor. The study also showed that a fatty liver from rats drinking $\mathrm{H}_{2}$ rich water contained less oxidative stress marker proteins and looked healthier compared to fat rats that did not receive $\mathrm{H}_{2}$ enriched water.

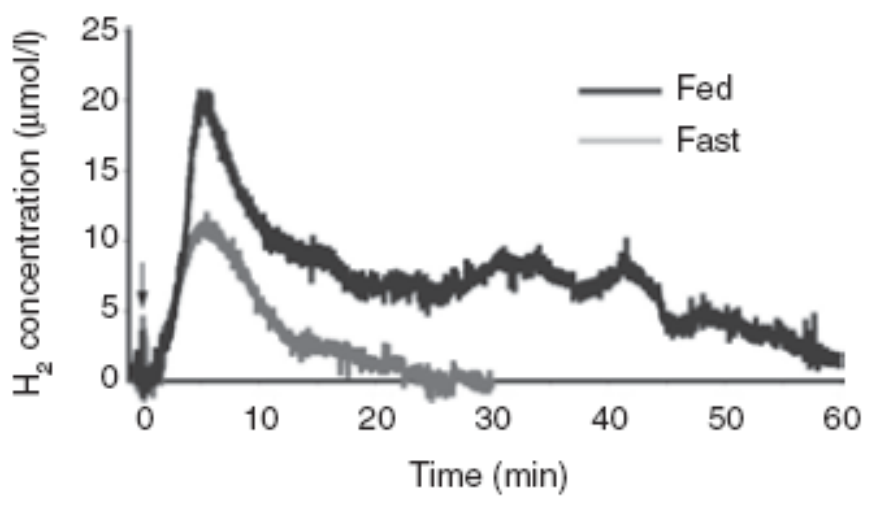

Fig. 2. $\mathrm{H}_{2}$ concentration measured in rat liver of a fed and an overnight-fasted rat. (Reprinted from Obesity, Vol 19, N. Kamimura, K. Nishimaki, I. Ohsawa, S. Ohta, Molecular hydrogen improves obesity and diabetes by inducing hepatic FGF21 and stimulating energy metabolism in db/db mice, p. 1396-1403 (ref 31). Copyright (2011), with permission from John Wiley \& Sons, Inc.).

Terasaki et al. have used the $\mathrm{H}_{2}$ microsensor to study the radioprotective effects of $\mathrm{H}_{2}$ for human (in vitro) and mice (in vivo) lung fibrosis [32]. The protective effect of $\mathrm{H}_{2}$ during lung damage induced by irradiation was also investigated with $\mathrm{H}_{2}-\mathrm{N}$ by directly inserting the sensor 
into mouse lung. They pointed out that $\mathrm{H}_{2}$, with no known toxic side effects, effectively protects cells and lungs of mice from oxidative stress and damage caused by irradiation because of the rapid diffusion of $\mathrm{H}_{2}$ across cell membranes and its reaction with cytotoxic ROS. In another study, an examination of the role of $\mathrm{H}_{2}$ inhalation for $\mathrm{O}_{2}$ deficit induced heart injuries also used the same sensor and approach [33]. Oharazawa and coworkers have used the $\mathrm{H}_{2}$ microsensor to monitor the $\mathrm{H}_{2}$ concentration in eye drops to study $\mathrm{H}_{2}$ 's protection of the retina [34]. The $\mathrm{H}_{2}$ measurement was made by immersion of the $\mathrm{H}_{2}$ sensor into the solution. Itoh et al. have used the $\mathrm{H}_{2}-\mathrm{N}$ microsensor in a similar way to abolish an immediate-type allergic reaction in mice [35]. Furthermore, if $\mathrm{H}_{2}$ monitoring has to take place under muscle, where $\mathrm{H}_{2}$ detection is difficult through skin, the tip protected needle sensor $\left(\mathrm{H}_{2}-\mathrm{NP}\right)$ can be used to pierce underneath the muscle without the danger of damaging the sensor tip.

In this relatively new field of biomedical sensing of $\mathrm{H}_{2}$ using electrochemical sensors, considerable research is ongoing to further improve the sensitivity, selectivity, response time, reliability, life-time, and cost. A wireless sensor network was reported in 2003 for atmospheric $\mathrm{H}_{2}$ sensing [36]. The sensor network consists of Ti nanotubes and $\mathrm{Pt}$ electrodes. $\mathrm{H}_{2}$ concentrations from $0 \mathrm{ppm}$ to $500 \mathrm{ppm}$ were correlated with the electrical resistance from $245 \Omega$ to $10.23 \mathrm{k} \Omega$. However, no wireless $\mathrm{H}_{2}$ sensor has been developed for in vivo $\mathrm{H}_{2}$ sensing so far. As more biological functions/applications of $\mathrm{H}_{2}$ are discovered, we believe new electrochemical $\mathrm{H}_{2}$ sensors, including wireless $\mathrm{H}_{2}$ sensors will be developed to better serve biomedical applications.

\section{Chemochromic semiconductor sensors}

Although the direct optical detection of $\mathrm{H}_{2}$ is not easy due to its lack of light absorption in the ultraviolet-visible or infrared region, various chemochromic devices that undergo color changes 
upon exposure to $\mathrm{H}_{2}$ have been developed [12, 37-40]. For example, $\mathrm{WO}_{3}$ films change their color from greenish yellow to blue when exposed to $\mathrm{H}_{2} . \mathrm{WO}_{3}, \mathrm{MoO}_{3}, \mathrm{Nb}_{2} \mathrm{O}_{5}, \mathrm{~V}_{2} \mathrm{O}_{5}$ and noble metals such as Pd, Pt, Ir, and Rh are extensively used for this purpose. The sensing mechanisms involve reduction of the metal oxides by $\mathrm{H}_{2}$ in the presence of a catalyst. Take $\mathrm{Pd} / \mathrm{WO}_{3}$ as an example where $\mathrm{H}_{2}$ gas is dissociated at room temperature on the surface of Pd catalyst into $\mathrm{H}$ atoms (eq 1) that diffuse into the underlying transition metal oxide film to reduce $\mathrm{WO}_{3}$ causing it to change color to bronze (eq 2). The reaction mechanism can be written as follows:

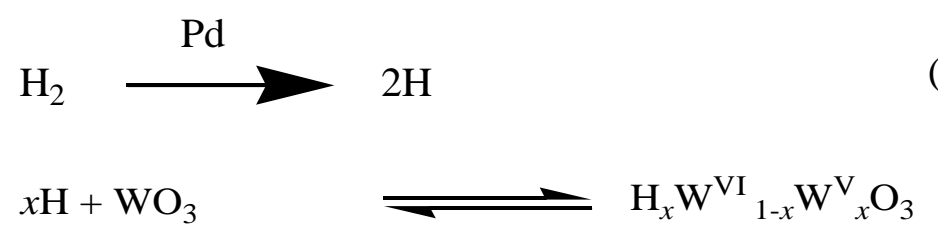

Hoagland et al. have developed a $\mathrm{H}_{2}$ gas indicator with multi-layered structure that is commercially available from Element One. The sensor comprises layers of $\mathrm{H}_{2}$ sensitive material such as the oxides of vanadium, yttrium, tungsten, and molybdenum, a catalyst such as $\mathrm{Pd}, \mathrm{Pt}, \mathrm{Ni}$, and $\mathrm{Rh}$, and a protective molecular diffusion barrier such as a polymer film [41]. A typical thin film indicator consists of a transparent polymer substrate, a $500 \mathrm{~nm}$ thick layer of tungsten oxide, a $3 \mathrm{~nm}$ layer of palladium catalyst, and a $100 \mathrm{~nm}$ thick protective coating of poly-tetrafluoroethylene (PTFE). Exposure to $\mathrm{H}_{2}$ causes the color to change from light off-white to dark blue. They also developed a reversible $\mathrm{H}_{2}$ sensor that returns to the original off-white color after exposure for $16 \mathrm{~h}$ in air due to oxidation by atmospheric oxygen. The reversible $\mathrm{H}_{2}$ sensor is reusable, which reduces cost. The color change of the irreversible $\mathrm{H}_{2}$ sensor can last for several weeks. The reversible/irreversible systems are based on different metal oxides/catalysts. These sensors can detect $\mathrm{H}_{2}$ as low as $300 \mathrm{ppm}$, which has made them useful as simple visual sensors for detection of $\mathrm{H}_{2}$ leaks in tank storage, pipe lines, fuel cells, and so on in industry. They have been developed in different configurations such as $\mathrm{H}_{2}$ tapes, paints, decals, thin coatings, 
indicator tags and warning signs for various applications. The detection method does not require electronic circuitry and is simple, visible, low cost, flexible, and easily implemented.

We have used the visual $\mathrm{H}_{2}$ sensor developed by Element One to monitor the $\mathrm{Mg}$ alloy corrosion process during in vivo testing with the subcutaneous mouse model that was described in the previous section. The visual $\mathrm{H}_{2}$ sensor was tested by positioning it on the skin directly above a Mg sample implanted under the skin of an anesthetized mouse. The color of the visual sensor changes from gray to dark blue as it is exposed to $\mathrm{H}_{2}$ generated from the $\mathrm{Mg}$ alloy biodegrading process (Fig. 1c-d). The color response of the sensor outlines the region of $\mathrm{H}_{2}$ permeation from the biodegrading $\mathrm{Mg}$ through the skin. This method provides a rapid, visual, noninvasive, easily performed measurement of $\mathrm{H}_{2}$. It takes advantage of the degradation mechanism of the main metal component, $\mathrm{Mg}$, which generates $\mathrm{H}_{2}$ gas that permeates through the skin adjacent to the implant at a low level. This low cost, simple method of monitoring the dissolution of biodegradable implants would facilitate the development of biodegradable materials, especially in animal studies where in vivo biodegradation is tested and is potentially useful for monitoring biodegradation of implants in patients.

Seibert et al. have developed a screen procedure based on a chemichromic $\mathrm{WO}_{3}$ film to identify $\mathrm{H}_{2}$-producing mutants with increased $\mathrm{O}_{2}$ pressure [42]. An agar plate containing different algal colonies was covered with filter paper onto which a grid was placed (Fig. 3a). The chemochromic film was placed on filter paper which covers the different algal colonies (Fig. 3b), then illuminated with light induced $\mathrm{H}_{2}$ production by the individual algal colonies. The color of the $\mathrm{WO}_{3}$ chemochromic film changed to purple (seen as black in Fig. 3c) in the presence of $\mathrm{H}_{2}$ generated by the algal colonies. After exposure to air for $5 \mathrm{~min}$, the chemochromic film returned to its original color (Fig. 3d), which indicates reversibility of the sensor film. The study 
demonstrated that the chemochromic film is sensitive enough to detect nanomoles of $\mathrm{H}_{2}$ and has the potential to rapidly screen large numbers of colonies for $\mathrm{H}_{2}$ production capacity. The technique has been used to screen and isolate large numbers of $\mathrm{H}_{2}$ producing mutants of $\mathrm{C}$. reinhardtii colonies.
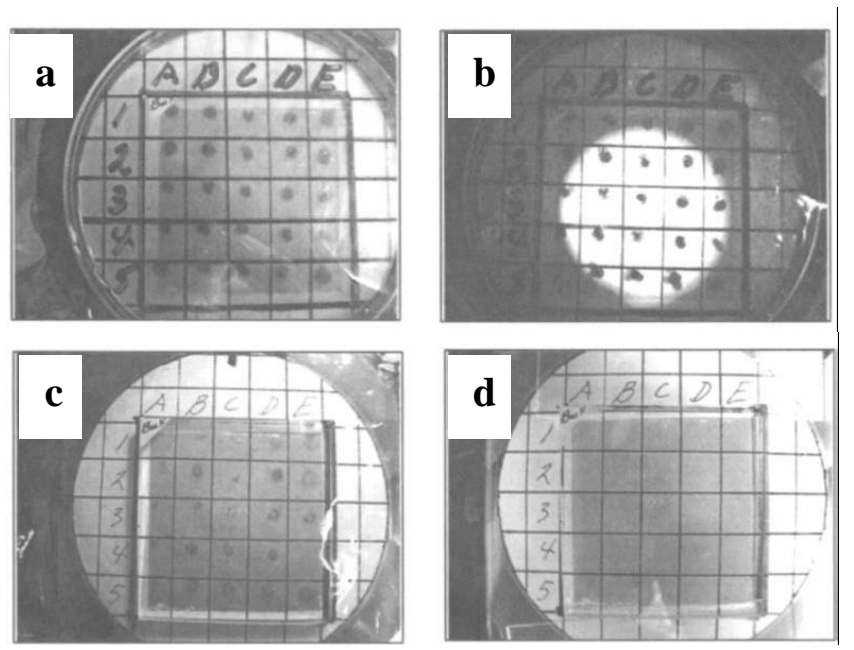

Fig. 3. Chemochromic film screen for $\mathrm{H}_{2}$-producing algal colonies. (a) Plate of individual algal colonies on agar. Grid placed on filter paper covering the algal colonies to allow easy identification of individual colonies. (b) Chemochromic film placed on top of the filter paper/grid and illuminated from the bottom of the plate to induce $\mathrm{H}_{2}$ evolution by the algal colonies. (c) Chemochromic film and grid removed from the plate containing the algal colonies for better observation of the purple spots on the film, which correspond to areas sensitized by $\mathrm{H}_{2}$ evolved by the colonies. Note differences in intensity of the spots, which correspond to the amount of $\mathrm{H}_{2}$ produced by the colony. (d) Sensitized film after exposure to air for $5 \mathrm{~min}$. The spots disappeared, demonstrating that they were exposed to $\mathrm{H}_{2}$. (Reprinted from Biohydrogen, Development of selection and screening procedures for rapid identification of $\mathrm{H}_{2}$-producing algal mutants with increased $\mathrm{O}_{2}$ tolerance, Chapter 30, 1998, p. 227-234, M. Seibert, T. Flynn, D.K. Benson, C. Tracy, M.L. Ghirardi, (ref.42). With permission from Springer). 


\section{Color indicator sensors}

Recently, a simple method employing a color indicator and $\mathrm{H}_{2}$-oxidation catalyst has been developed and used for the detection of biological $\mathrm{H}_{2}$ production [43-44]. The evaluated color indicators and catalysts are summarized in Table 1 . This method involves hydrogenation of the color agent in the presence of the catalyst; the colors of the color agent before and after the hydrogenation are different. Generally, unsaturated double bonds between chromophore and auxochromes of a color agent are involved in the color change. For example, the color of methlylene blue is blue in an aqueous solution; hydrogenation reduces the methlylene blue to colorless leucomethylene blue as follows:<smiles></smiles>

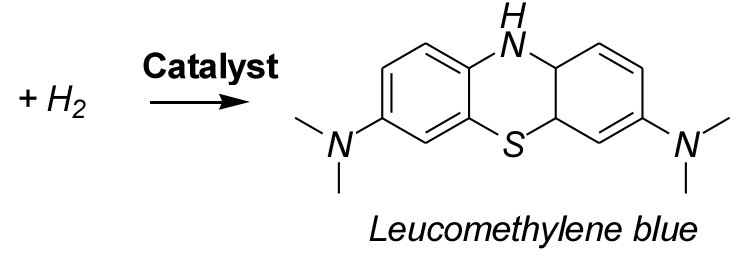

Table 1. Color indicators and catalysts

\begin{tabular}{|c|c|c|}
\hline Color Indicator & Color change & Catalyst \\
\hline Methylene blue & 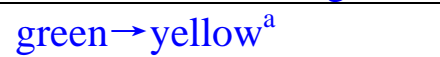 & sufonated Wilkinson's catalyst $^{\mathrm{a}}$; \\
\hline Methylene blue & Blue $\rightarrow$ colorless $^{\mathrm{b}}$ & colloidal $\mathrm{Pt}^{\mathrm{b}} ;$ sulfonated iridium \\
\hline neutral red & red $\rightarrow$ brown $^{\text {a }}$ & cyclooactadiene \\
\hline methyl orange & orange $\rightarrow$ brown $^{a}$ & triphenylphosphine ${ }^{\mathrm{c}} ; \quad$ sulfonated \\
\hline crystal violet & violet $\rightarrow$ yellow $^{\text {a }}$ & $\begin{array}{lr}\text { rhodium } & \text { cyclooctadiene } \\
\text { triphenylphosphine }^{c} ; & \text { sulfonated }\end{array}$ \\
\hline Victoria blue & Pale violet $\rightarrow$ pale brown ${ }^{a}$ & ruthenium triphenylphosphine ${ }^{c}$; \\
\hline Evan's Blue & blue $\rightarrow$ yellow $^{\mathrm{a}}$ & Azotobacter vinlandiic; Ralstonia \\
\hline Bromphenol blue & Pale violet $\rightarrow$ brown $^{\text {a }}$ & eutropha ${ }^{c}$ \\
\hline Thymol blue & yellow $\rightarrow$ brown $^{\text {a }}$ & \\
\hline Orange II, & orange $\rightarrow$ pale brown ${ }^{a}$ & \\
\hline methyl purple, & - & \\
\hline WST-1,3,5,9,11, & - & \\
\hline XTT & - & \\
\hline
\end{tabular}


Note: ${ }^{c}$ is the reported catalysts used for the color indicator hydrogenation, however, the color indicators are not specified.

Katsuda et al. examined a series of color indicators in the presence of water soluble sulfonated Wilkinson's catalyst for screening $\mathrm{H}_{2}$ producing microorganisms [44]. The typical color changes of indicators in $0.8 \mathrm{mM}$ sulfonated Wilkinson's catalyst aqueous solution before and after $\mathrm{H}_{2}$ exposure are shown in Fig. 4. This method has been used for the detection of $\mathrm{H}_{2}$ gas generated by $\mathrm{H}_{2}$-producing microorganisms Rhodobacter capsulatus $\mathrm{ST}-410$, which is simple, visual and effective. The decoloring process has been characterized by UV-visible spectroscopy. The absorption band of methyl orange at $520 \mathrm{~nm}$ disappeared after exposure to $\mathrm{H}_{2}$ generated by microorganisms Rhodobacter capsulatus ST-410 within $45 \mathrm{~h}$. Although the procedure is somewhat time consuming, visual detection is much easier compared with gas chromatography.
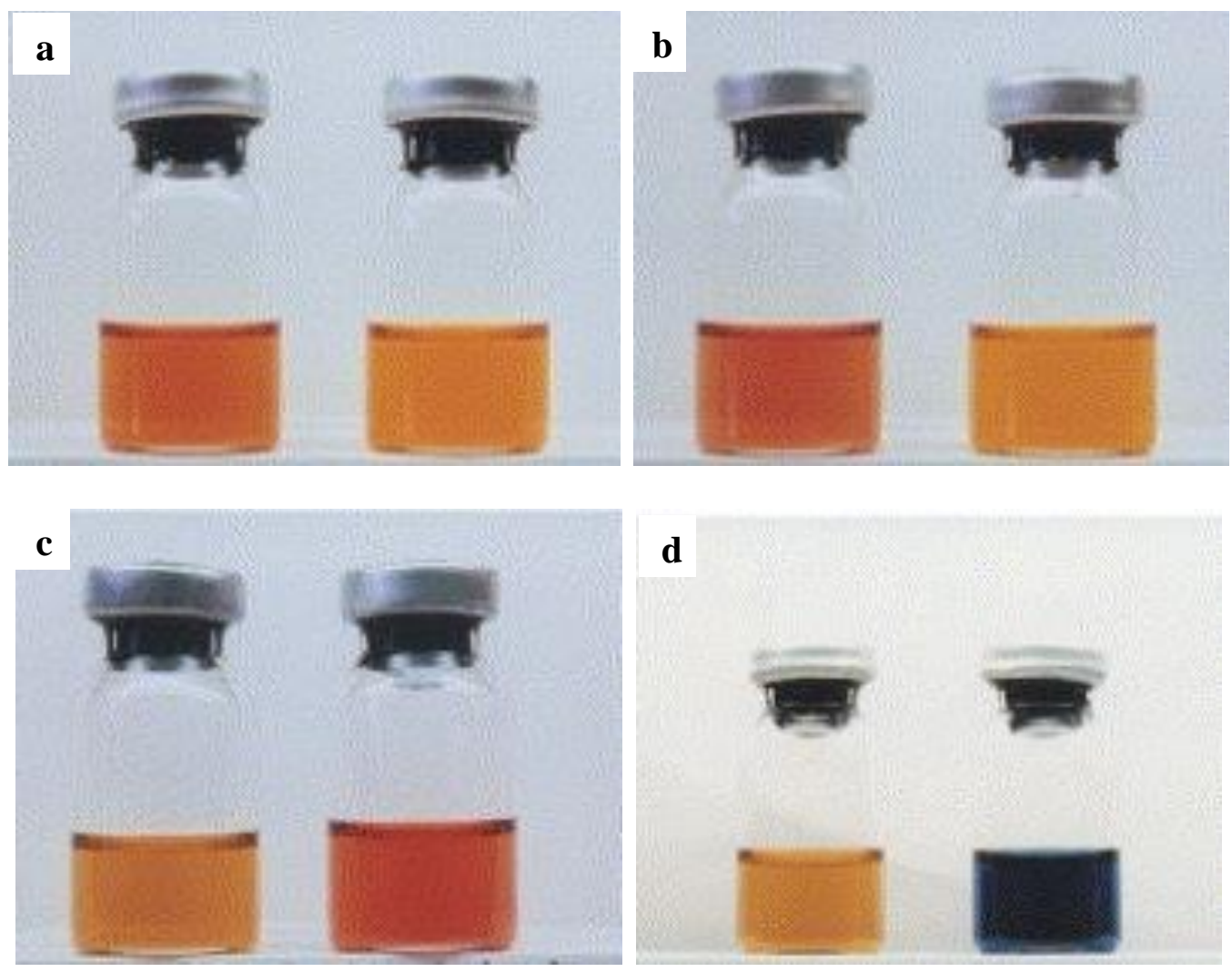


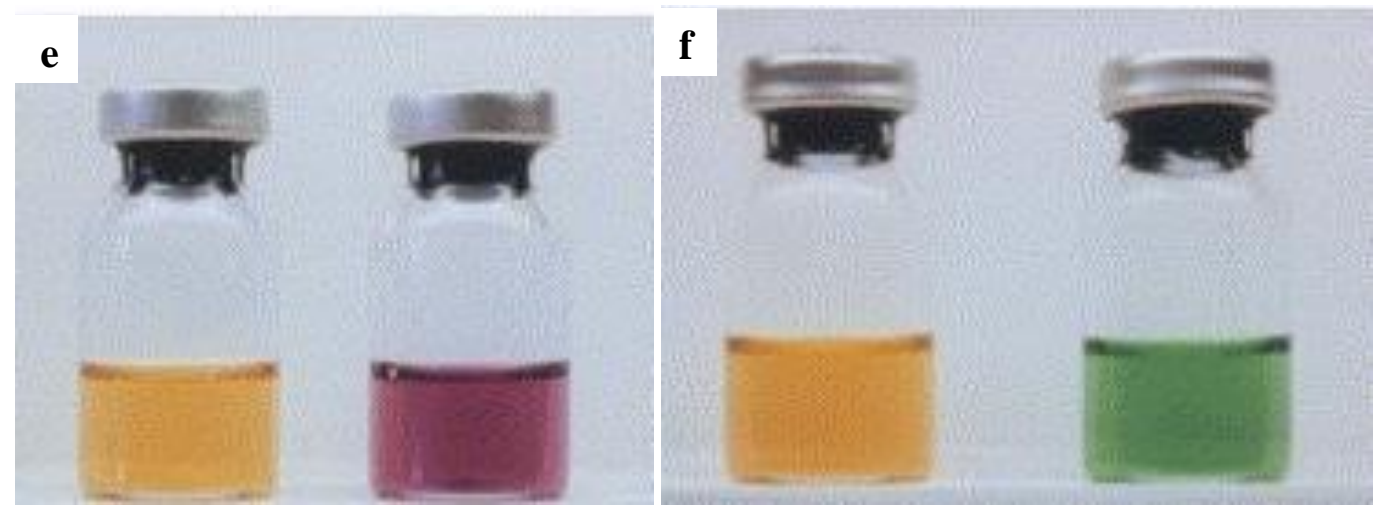

Fig. 4. Color changes of indicators in the presence of sulfonated Wilkinson's catalytic hydrogenation in aqueous solution $(0.8 \mathrm{mM})$ at room temperature. Left and right vials show the color of the solution after and before the $\mathrm{H}_{2}$ exposure. Color indicators: (a) methyl orange; (b) methyl red sodium; (c) neutral red; (d) Evan's blue; (e) crystal violet; (f) methylene blue. (Reprinted from J. Biosci. Bioeng., Vol 102, T. Katsuda, H. Oshima, M. Azuma, J. Kato, New detection method for hydrogen gas for screening hydrogen-producing microorganisms using water-soluble Wilkinson's catalyst derivative, p. 220-226 (ref 44). Copyright (2006), with permission from Elsevier.).

Schrader and coworkers have developed a high-throughput screening assay for assessing biological $\mathrm{H}_{2}$ production [43]. This assay comprises a 96-well micro plate with water soluble hydrogenation catalyst and the color indicator on the top (catalysts and color indicators are listed in Table 1), $\mathrm{H}_{2}$ producing cynobacteria in another 96-well microplate at the bottom, and a membrane in between. The $\mathrm{H}_{2}$ generated by cyanobacteria diffused through the membrane into the upper plate, and changing the color of the indicator (WST-3) which is quantified with a microplate reader. This assay is reproducible and semiquantitative, sensitive down to the 20 nmol $\mathrm{H}_{2}$, and largely unaffected by oxygen, carbon dioxide and volatile fatty acids in the biological systems. This setup avoids catalyst microbial inhibition, and the color change is more 
stable due to the physical separation of the indicator solution from the cells so it is not affected by cellular interactions or nonvolatile metabolites. This assay provides a reliable, versatile method for screening $\mathrm{H}_{2}$ production by a large number of microbial or algal cultures. It can be adapted to various physical configurations and diverse applications, such as screening mutant strains or environmental samples. It can also be potentially used for the rapid evaluation of the effects of various factors such as $\mathrm{pH}$ on production of $\mathrm{H}_{2}$ in biological environments.

Recently, Seo and coworkers used colloidal platinum as the catalyst to hydrogenate methylene blue in an aqueous solution to determine $\mathrm{H}_{2}$ concentration in water [45]. The $\mathrm{H}_{2}$ concentration was also determined by oxidimetry and electrochemistry and the results were correlated. This detection method performs as effectively as the electrochemical method. The combination of the color indicator and the water soluble catalyst as the $\mathrm{H}_{2}$ biological sensor is promising. The detection method is simple, effective and visible, and requires no expensive equipment such as for gas chromatography and electrochemistry. The hydrogenation of the color indicator does not involve other side reactions.

\section{Comparison of electrochemical, chemochromic metal oxide and color indicator sensors}

Electrochemical sensors have the highest sensitivity among these commercial $\mathrm{H}_{2}$ sensors. The sensors can be calibrated by different $\mathrm{H}_{2}$ concentrations in water solution, making the measurements easily quantified. Electrochemical sensors have been used for biological studies in a subcutaneous implant mouse model to monitor the biodegradation process of magnesium alloys and to determine $\mathrm{H}_{2}$ concentrations in medical applications of $\mathrm{H}_{2}$. The drawbacks of this sensor are fragility, cost, and decreasing sensitivity with time,.

Semiconductor metal oxide sensors are low cost, small, easier to fabricate, with high sensitivity for use in $\mathrm{H}_{2}$ safety applications; however, the operating conditions are harsh. Most of 
them require high temperature to obtain stable resistance or conductivity. These harsh operation conditions require more power consumption and pose potential hazards, which limits their application for bioanalysis such as in vivo measurements. With the addition of noble metals in the metal oxides, the operation temperature is significantly lowered to room temperature or near room temperature. This property makes them more useful for bioanalytical applications in the future. The $\mathrm{H}_{2}$ chemochromic sensors have fast response and higher sensitivity. So far, the chemochromic sensors are based on two kinds of $\mathrm{H}_{2}$ materials: Pt-doped $\mathrm{WO}_{3}$ thin films or other formats and palladium-alloy thin films. The $\mathrm{H}_{2}$ chemochromic sensors based on pure palladium are safe, and efficient; however, they usually suffer from the Pd film's fatal fracture due to the $\alpha$ $\beta$ phase transition. In addition, pure Pd films easily peel off with exposure to $\mathrm{H}_{2}$ due to poor adhesive to the optic fiber. These behaviors contribute to more irreversible response, which leads to hysteresis effects during the $\mathrm{H}_{2}$ adsorption and desorption process. Therefore, different films such as PTFE have been applied to protect the Pd films, and improve sensor lifetime.

The color indicator $\mathrm{H}_{2}$ sensors are comprised of a catalyst such as sulfonated Wilkinson's catalyst and a color indicator. The response time for this type sensor is short and the sensors have good sensitivity. They have been used for detection of biological $\mathrm{H}_{2}$ production. The drawback of this sensor is the use of heavy metal catalysts, which can cause microbial inhibition. The color indicator sensors can be used in aqueous solution, which is more compatible with the biological environment. Overall, none of these sensors demonstrate optimum performance under all conditions. Therefore, the selection of sensor type depends on the operating requirements of the application such as the response time, measuring range, detection limit, convenience, ruggedness, etc. 


\section{Conclusion}

The increasing activity in $\mathrm{H}_{2}$ sensing for bioanalytical applications is being driven by the growing interest in studying the potential biological and health benefits provided of $\mathrm{H}_{2}$ that have been reported. The development of biodegradable implants made of $\mathrm{Mg}$ whose corrosion can be easily monitored by transdermal $\mathrm{H}_{2}$ detection also provides impetus to the development of appropriate $\mathrm{H}_{2}$ sensors. The $\mathrm{H}_{2}$ detection properties of different categories of $\mathrm{H}_{2}$ sensors based on electrochemistry, chemochromic metal oxides and color indicators have been reviewed. Electrochemical sensors that are very sensitive and very selective are commercially available. However some probes are fragile and loss of sensitivity in the long term is an issue. Metal oxide based sensors that are used for many industrial applications operate at very high temperatures, which is problematic for many biological applications. Doping the metal oxides with noble metal lowers the operating condition to room temperature, which provides promise for biological applications. However, selectivity is still a problem due to interference from other reducing gases such as hydrogen sulfide. $\mathrm{H}_{2}$ detection by optical and color indicator sensors is simple, effective and provides a visible signal that can be observed by the naked eye. A limitation of this type of sensor is interference by heavy metals in cell cultures. Therefore, understanding the limitations of the different $\mathrm{H}_{2}$ sensors is needed for good sensor selection to best serve a particular application. $\mathrm{H}_{2}$ sensors will play increasingly important roles in biological applications such as studying the effects of $\mathrm{H}_{2}$ on biological systems, monitoring biodegradable alloy corrosion in vivo and in vitro by a $\mathrm{H}_{2}$ sensor to provide feedback for the design of new alloys and improvement in the current alloys, and monitoring $\mathrm{H}_{2}$ concentration changes with time in blood to provide real-time measurement information for the study of $\mathrm{H}_{2}$ benefits for medicine. 


\section{Acknowledgement}

The authors acknowledge financial support provided by National Science Foundation grant NSF ERC 0812348 that supports the Engineering Research Center for Revolutionizing Metallic Biomaterials. The authors thank Element One for providing the hydrogen sensitive materials.

\section{References}

[1] I. Ohsawa, M. Ishikawa, K. Takahashi, M. Watanabe, K. Nishimaki, K. Yamagata, K. Katsura, Y. Katayama, S. Asoh, S. Ohta, Hydrogen acts as a therapeutic antioxidant by selectively reducing cytotoxic oxygen radicals, Nat. Med., 13 (2007) 688-694.

[2] S.M. Ostojic, Molecular hydrogen in hports medicine: new therapeutic perspectives, Int. J. Sports Med., 36 (2015) 273-279.

[3] S.M. Ostojic, Molecular hydrogen: An inert gas turns clinically effective, Ann. Med., 47 (2015) 301 304.

[4] S. Ohta, Molecular hydrogen as a preventive and therapeutic medical gas: initiation, development and potential of hydrogen medicine, Pharmacol. Therapeut., 144 (2014) 1-11.

[5] S. Ohta, Recent progress toward hydrogen medicine: potential of molecular hydrogen for preventive and therapeutic applications, Curr. Pharm. Design, 17 (2011) 2241-2252.

[6] K. Fujita, T. Seike, N. Yutsudo, M. Ohno, H. Yamada, H. Yamaguchi, K. Sakumi, Y. Yamakawa, M.A. Kido, A. Takaki, T. Katafuchi, Y. Tanaka, Y. Nakabeppu, M. Noda, Hydrogen in drinking water reduces dopaminergic neuronal loss in the 1-methyl-4-phenyl-1,2,3,6-tetrahydropyridine mouse model of parkinson's disease, Plos One, 4 (2009) e7247.

[7] H.J. Liu, R. Colavitti, I.I. Rovira, T. Finkel, Redox-dependent transcriptional regulation, Circ. Res., 97 (2005) 967-974.

[8] H. Sauer, M. Wartenberg, J. Hescheler, Reactive oxygen species as intracellular messengers during cell growth and differentiation, Cell. Physiol. Biochem., 11 (2001) 173-186.

[9] R.I. Salganik, The benefits and hazards of antioxidants: Controlling apoptosis and other protective mechanisms in cancer patients and the human population, J. Am. Coll. Nutr., 20 (2001) 464s-472s.

[10] C.J. Rollins, D.M. Klurfeld, D. Epner, K.L. Fritsche, R.L. Salganik, D.J. Strobl, K.N. Prasad, M.B. Zemel, M.L. Masor, K.D.R. Setchell, R.J. Nicolosi, J. Cunningham, B.H. Arjmandi, K.B. Wheeler, V. Vuksan, The benefits and hazards of antioxidants: Controlling apoptosis and other protective mechanisms in cancer patients and the human population-Discussion, J. Am. Coll. Nutr., 20 (2001) 473s-475s.

[11] Y.J. Chen, Z.G. Xu, C. Smith, J. Sankar, Recent advances on the development of magnesium alloys for biodegradable implants, Acta Biomater., 10 (2014) 4561-4573.

[12] T. Hubert, L. Boon-Brett, G. Black, U. Banach, Hydrogen sensors-A review, Sens. Actuators, B, 157 (2011) 329-352.

[13] L. Boon-Brett, J. Bousek, G. Black, P. Moretto, P. Castello, T. Hubert, U. Banach, Identifying performance gaps in hydrogen safety sensor technology for automotive and stationary applications, Int. J. Hydrogen Energy, 35 (2010) 373-384.

[14] G. Korotcenkov, S. Do Han, J.R. Stetter, Review of electrochemical hydrogen sensors, Chem. Rev., 109 (2009) 1402-1433. 
[15] J.F. Witty, Microelectrode Measurements of Hydrogen Concentrations and Gradients in Legume Nodules, J. Exp. Bot., 42 (1991) 765-771.

[16] N.P. Revsbech, Analysis of microbial communities with electrochemical microsensors and microscale biosensors, Method Enzymol, 397 (2005) 147-166.

[17] J.W. Olson, R.J. Maier, Molecular hydrogen as an energy source for Helicobacter pylori, Science, 298 (2002) 1788-1790.

[18] R.J. Maier, J. Olson, A. Olczak, Hydrogen-oxidizing capabilities of Helicobacter hepaticus and in vivo availability of the substrate, J. Bacteriol., 185 (2003) 2680-2682.

[19] M. Pelzer, M. Larsen, P.F. Friedrich, A.T. Bishop, Measurement of bone blood flow using the hydrogen washout technique - Part I: Quantitative evaluation of tissue perfusion in the laboratory rat, J. Orthopaed. Res., 26 (2008) 741-745.

[20] http://erc.ncat.edu.

[21] J. Kuhlmann, I. Bartsch, E. Willbold, S. Schuchardt, O. Holz, N. Hort, D. Hoche, W.R. Heineman, F. Witte, Fast escape of hydrogen from gas cavities around corroding magnesium implants, Acta Biomater., 9 (2013) 8714-8721.

[22] G.L. Song, Control of biodegradation of biocompatable magnesium alloys, Corros. Sci., 49 (2007) 1696-1701.

[23] W.R. Heineman, T. Wang, D. Zhao, Z. Dong, Transdermal hydrogen sensing for monitoring biodegradable magnesium biomedical implants, Abstr. Pap. Am. Chem. S., 250 (2015) 186-Anyl.

[24] W.R. Heineman, T. Wang, D. Zhao, J. Kuhlmann, Z. Dong, V.N. Shanov, D. Chou, D. Hong, P.N. Kumta, Y. Yun, Monitoring Corrosion of Biodegradable Magnesium Implants with a Hydrogen Gas Sensor, Pittcon Conference, (2015).

[25] W.R. Heineman, J. Kuhlmann, Guo X, A. Doepke, T. Wang, K. Ojo, R.T. Voorhees, S.K. Pixley, Z. Dong, V.N. Shanov, F. Witte, Electrochemical Sensors for Developing Biodegradable Implants, Pittcon Conference, (2014).

[26] T. Wang, D. Zhao, Z. Dong, V.N. Shanov, Y. Yun, P.N. Kumta, W.R. Heineman, Monitoring Biodegradable Metal Alloys Using Analytical Methods, Pittcon Conference, (2015).

[27] D. Zhao, T. Wang, X. Guo, J. Kuhlmann, A. Doepke, Z. Dong, V.N. Shanov, W.R. Heineman, Monitoring Biodegradation of Magnesium Implants with Sensors, JOM-J. Min. Met. S., In press (2016). [28] K. Hayashida, M. Sano, I. Ohsawa, K. Shinmura, K. Tamaki, K. Kimura, J. Endo, T. Katayama, A. Kawamura, S. Kohsaka, S. Makino, S. Ohta, S. Ogawa, K. Fukuda, Inhalation of hydrogen gas reduces infarct size in the rat model of myocardial ischemia-reperfusion injury, Biochem. Biophys. Res. Commun., 373 (2008) 30-35.

[29] M. Kajiya, K. Sato, M.J.B. Silva, K. Ouhara, P.M. Do, K.T. Shanmugam, T. Kawai, Hydrogen from intestinal bacteria is protective for Concanavalin A-induced hepatitis, Biochem. Biophys. Res. Commun., 386 (2009) 316-321.

[30] M. Kajiya, M.J.B. Silva, K. Sato, K. Ouhara, T. Kawai, Hydrogen mediates suppression of colon inflammation induced by dextran sodium sulfate, Biochem. Biophys. Res. Commun., 386 (2009) 11-15.

[31] N. Kamimura, K. Nishimaki, I. Ohsawa, S. Ohta, Molecular hydrogen improves obesity and diabetes by inducing hepatic FGF21 and stimulating energy metabolism in db/db mice, Obesity, 19 (2011) 1396-1403.

[32] Y. Terasaki, I. Ohsawa, M. Terasaki, M. Takahashi, S. Kunugi, D.D. Kang, H. Urushiyama, S. Amenomori, M. Kaneko-Togashi, N. Kuwahara, A. Ishikawa, N. Kamimura, S. Ohta, Y. Fukuda, Hydrogen therapy attenuates irradiation-induced lung damage by reducing oxidative stress, Am J Physiol-Lung C, 301 (2011) L415-L426.

[33] H.Y. Sun, L. Chen, W.P. Zhou, L.A. Hu, L.A. Li, Q.Q. Tu, Y.X. Chang, Q. Liu, X.J. Sun, M.C. Wu, H.Y. Wang, The protective role of hydrogen-rich saline in experimental liver injury in mice, J. Hepatol., 54 (2011) 471-480. 
[34] H. Oharazawa, T. Igarashi, T. Yokota, H. Fujii, H. Suzuki, M. Machide, H. Takahashi, S. Ohta, I. Ohsawa, Protection of the retina by rapid diffusion of hydrogen: administration of hydrogen-loaded eye drops in retinal ischemia-reperfusion Injury, Invest. Ophth. Vis. Sci., 51 (2010) 487-492.

[35] T. Itoh, Y. Fujita, M. Ito, A. Masuda, K. Ohno, M. Ichihara, T. Kojima, Y. Nozawa, M. Ito, Molecular hydrogen suppresses Fc epsilon RI-mediated signal transduction and prevents degranulation of mast cells, Biochem. Biophys. Res. Commun., 389 (2009) 651-656.

[36] C.A. Grimes, K.G. Ong, O.K. Varghese, X.P. Yang, G. Mor, M. Paulose, E.C. Dickey, C.M. Ruan, M.V. Pishko, J.W. Kendig, A.J. Mason, A sentinel sensor network for hydrogen sensing, Sensors, 3 (2003) 6982.

[37] M.H. Yaacob, M. Breedon, K. Kalantar-Zadeh, W. Wlodarski, Absorption spectral response of nanotextured $\mathrm{WO}_{3}$ thin films with Pt catalyst towards $\mathrm{H}_{2}$, Sens. Actuators, B, 137 (2009) 115-120.

[38] W.C. Hsu, C.C. Chan, C.H. Peng, C.C. Chang, Hydrogen sensing characteristics of an electrodeposited $\mathrm{WO}_{3}$ thin film gasochromic sensor activated by Pt catalyst, Thin Solid Films, 516 (2007) 407-411.

[39] W.J. Buttner, M.B. Post, R. Burgess, C. Rivkin, An overview of hydrogen safety sensors and requirements, Int. J. Hydrogen Energy, 36 (2011) 2462-2470.

[40] R. Ab Kadir, R.A. Rani, M.M.Y.A. Alsaif, J.Z. Ou, W. Wlodarski, A.P. O'Mullane, K. Kalantar-zadeh, Optical gas sensing properties of nanoporous $\mathrm{Nb}_{2} \mathrm{O}_{5}$ films, ACS Appl. Mater. Inter., 7 (2015) 4751-4758. [41] W. Hoagland, Hydrogen gas indicator system, U.S. patent 6895805, USA 2005.

[42] M. Seibert, T. Flynn, D.K. Benson, C. Tracy, M.L. Ghirardi, Development of selection and screening procedures for rapid identification of $\mathrm{H}_{2}$-producing algal mutants with increased $\mathrm{O}_{2}$ tolerance, Biohydrogen, Plenum Press, (1998) 227-234.

[43] P.S. Schrader, E.H. Burrows, R.L. Ely, High-throughput screening assay for biological hydrogen production, Anal. Chem., 80 (2008) 4014-4019.

[44] T. Katsuda, H. Oshima, M. Azuma, J. Kato, New detection method for hydrogen gas for screening hydrogen-producing microorganisms using water-soluble Wilkinson's catalyst derivative, J. Biosci. Bioeng., 102 (2006) 220-226.

[45] T. Seo, R. Kurokawa, B. Sato, A convenient method for determining the concentration of hydrogen in water: use of methylene blue with colloidal platinum, Med. Gas Res., 2 (2012) doi:10.1186/20459912-1182-1181. 